\title{
A COMPARATIVE ANALYSIS OF SERUM LIPIDS IN PATIENTS WITH CHRONIC HEPATITIS C, NONALCOHOLIC FATTY LIVER DISEASE AND HEALTHY CONTROLS
}

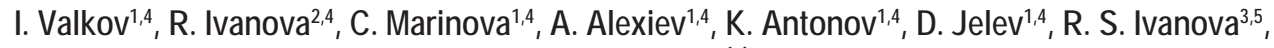 \\ and L. Mateva ${ }^{1,4}$ \\ ${ }^{1}$ Clinic of Gastroenterology, University Hospital Sv. Ivan Rilski, Medical University - Sofia \\ ${ }^{2}$ Clinic of Cardiology, University Hospital Alexandrovska, Medical University - Sofia \\ ${ }^{3}$ Laboratory of Clinical Pathology, University Hospital Sv. Ivan Rilski, Medical University - Sofia \\ ${ }^{4}$ Department of Internal Diseases, Faculty of Medicine, Medical University - Sofia \\ ${ }^{5}$ Clinical Center of Endocrinology and Gerontology, Faculty of Medicine, Medical University - Sofia
}

\begin{abstract}
Serum lipids abnormalities are widespread among patients with chronic hepatitis $\mathrm{C}(\mathrm{CHC})$, but the impact of concomitant hepatic steatosis [steatosis, nonalcoholic steatosis (NAS)], as well as distinctions between it and nonalcoholic fatty liver disease (NAFLD) are not well established yet. The aim of the study was to assess and compare the serum lipids in patients with genotype $1 \mathrm{CHC}$ with and without steatosis, those with NAFLD, and healthy controls (HC). A total of 1010 subjects were included in this study: 366 CHC genotype 1 patients with steatosis $(n=227)$ and without steatosis $(n=139)$, 403 NAFLD patients, and $241 \mathrm{HC}$ without fatty liver or other disease, matched for age and gender. Serum lipids, body mass index (BMI), components of metabolic syndrome (MS), and serum insulin levels were evaluated. In addition serum lipoprotein (a) [Lp(a)] levels were studied in 112 CHC and 80 NAFLD patients. The mean levels of total cholesterol, $L D L$-cholesterol and triglycerides $(\mathrm{Tg})$ were higher and the mean levels of HDLcholesterol were lower in all patients with steatosis (CHC and NAFLD) than in CHC cases without steatosis ( $p<0.05$ and $p=0.001$, resp.). Higher prevalence and severity of lipid abnormalities, including $L p(a)$, were observed in patients with NAFLD than in those with $\mathrm{CHC}(p<0.001)$. No difference was found between $\mathrm{CHC}$ patients without steatosis and $H C$. Higher prevalence and grade of glucose metabolic abnormalities were also observed in patients with NAFLD and CHC with steatosis than in cases without steatosis $(p<0.05$ and $p=0.001$, resp.). Lipid and glucose metabolic abnormalities in patients with $\mathrm{CHC}$ were dependent on steatosis. CHC with steatosis and NAFLD were associated with insulin resistant type dyslipidemia, with total cholesterol and LDL-cholesterol being generally lower in $\mathrm{CHC}$.
\end{abstract}

Key words: Hepatitis C Virus, Nonalcoholic Fatty Liver Disease, Metabolic Syndrome, Triglycerides, Low-density Lipoprotein, Lipoprotein(a)

Corresponding author: Ivan Valkov, MD, Clinic of Gastroenterology, University Hospital Sv. St. Ivan Rilski, e-mail: ivan.valkov@yahoo.co.uk 


\section{BACKGROUND}

C hronic hepatitis $\mathrm{C}(\mathrm{CHC})$ is a leading cause of liver cirrhosis and hepatocellular carcinoma (HCC), associated with a heavy disease burden. Hepatitis C virus (HCV) infection is also associated with hepatic steatosis [steatosis, nonalcoholic steatosis (NAS)], insulin resistance (IR) lipid and glucose abnormalities [1-3]. This cluster of dysmetabolic conditions differs from the "typical" metabolic syndrome and has been referred to as HCV-associated dysmetabolic syndrome. Hepatic steatosis is a frequent histological feature on liver biopsy in patients with $\mathrm{CHC}$ [3-5]. The reported prevalence of steatosis among patients with $\mathrm{CHC}$ ranges from to $40-86 \%$ (mean $55 \%$ ), the prevalence being higher among those infected with HCV genotype 3 than in patients infected with genotype 1. Despite being due to both viral and host factors, steatosis in $\mathrm{CHC}$ may be divided by pathogenesis into virus related, occurring in genotype $3 \mathrm{HCV}$ infection, and metabolically related in non-genotype $3 \mathrm{HCV}$ infection. In patients with genotype $1 \mathrm{CHC}$, steatosis is associated with an increased body mass index (BMI) and visceral obesity, while in those infected by HCV genotype 3 the degree of steatosis correlates with viral load and also resolves after eradication of HCV through treatment. $\mathrm{CHC}$ has been reported as a risk factor for atherosclerosis and both viral load and steatosis are independetly associated with carotid atherosclerosis [6].

Nonalcoholic fatty liver disease (NAFLD) is also accompanied by multiple metabolic derangements, among which insulin resistance has a major role. NAFLD is strongly associated with obesity, metabolic syndrome, type 2 diabetes mellitus (DM), increased cardiovascular risk and mortality [7]. Atherogenic dyslipidemia includes increased serum triglycerides, low-density lipoprotein cholesterol (LDL-C) and apo$B$ levels, decreased high-density lipoprotein cholesterol (HDL-c) levels and is typical for NAFLD [2, 8, 9]. In patients with genotype $1 \mathrm{CHC}$ and steatosis, the alterations of lipid profile may be influenced by the interaction of HCV infection and NAFLD [3]. Many studies have reported abnormal serum lipid levels, mainly hypocholesterolemia, in patients with $\mathrm{CHC}$. The impact of concomitant steatosis as well as distinctions between it and NAFLD are not well established yet.

\section{AIM}

The aim of our study was to assess and compare the serum lipids in patients with genotype $1 \mathrm{CHC}$ with and without steatosis, those with NAFLD, and healthy controls $(\mathrm{HC})$.

\section{MATERIAL AND METHODS}

A total of 1010 subjects were included in this study: 366 with genotype 1 and treatment - naïve $\mathrm{CHC}$ patients (165 men, 201 women; mean age 45.93 \pm 14.10 years, from 18 to 60 years) with steatosis $(n=227)$ and $\mathrm{CHC}$ without steatosis $(n=139) ; 403$ NAFLD patients (266 men, 141 women; mean age $43.99 \pm 11.32$ years, from 18 to 60 years) and 241 HC (154 men, 87 women; mean age $42.80 \pm 14.27$ years, from 18 to 60 years) without fatty liver and other diseases.

Diagnosis of $\mathrm{CHC}$ and NAFLD was based on the standard criteria [10, 11]. In all patients with $\mathrm{CHC}$, the diagnosis was confirmed by histology, as well as in 141 patients with NAFLD. Diagnosis of NAS was based on histology when more than $5 \%$ of the hepatocytes in the liver biopsy presented lipid droplets.

Serum lipids, including total cholesterol (TC), Tg, LDL-C and HDL-c were measured in all cases by standard methods. Lipoprotein a $[L p(a)]$ level was evaluated in 112 subjects with $\mathrm{CHC}$ (74 with steatosis and 38 without steatosis) and 80 - with NAFLD. Dyslipidemia was defined by any of the following abnormalities: TC > $5 \mathrm{mmol} / \mathrm{l}$, LDL-c $>3.5 \mathrm{mmol} / \mathrm{l}, \mathrm{HDL}-$ $\mathrm{c}<1.0 \mathrm{mmol} / \mathrm{l}$ for men and $1.3 \mathrm{mmol} / \mathrm{l}$ for women, and TG $>1.7 \mathrm{mmol} / \mathrm{l}$. Increased level of $L p(a)$ was defined as $>25 \mathrm{mg} / \mathrm{dl}$.

Body Mass Index (BMl; $\left.\mathrm{kg} / \mathrm{m}^{2}\right)$ and waist circumference $(\mathrm{cm})$ were evaluated by anthropometry. Overweight corresponded to $\mathrm{BMI}>25 \mathrm{~kg} / \mathrm{m}^{2}$ and obesity - to $\mathrm{BMI} \geq 30 \mathrm{~kg} / \mathrm{m}^{2}$. Metabolic syndrome (MS) and diabetes were diagnosed following the International Diabetes Federation (IDF) criteria [12, 13]. Serum fasting glucose and insulin levels were measured and homeostasis model assessment for insulin resistance (HOMA - IR) was calculated, using the following formula: HOMA-IR = fasting insulin $(\mathrm{mE} / \mathrm{l}) \mathrm{x}$ fasting plasma glucose $(\mathrm{mmol} / \mathrm{l}) / 22.5$. IR was defined by a value of HOMA-IR $>2.5$.

Statistical analysis of the data was performed using SPSS v.16 for descriptive, Student's t-test, MannWhitney $U$ test and correlation analyses. Values of probability $(p)$ less than 0.05 were considered to be statistically significant.

\section{RESULTS}

Lipid abnormalities in patients with $\mathrm{CHC}$ with and without steatosis, NAFLD and HC

The prevalence of dyslipidemia was significantly higher in patients with steatosis $(\mathrm{CHC}$ with steatosis and NAFLD) than those with $\mathrm{CHC}$ without steatosis 
and HC ( 1 < 0.001), except for TC and LDL-c in CHC patients with steatosis (Figure 1). The lipid profile of the patients with $\mathrm{CHC}+\mathrm{NAS}$ showed a high Tg level (22\%). Low HDL-c level (28\%) was more prevalent in comparison with the group of patients without steatosis and $\mathrm{HC}$, while the prevalence of high LDL-C $(14 \%)$ was lower. The percentages of patients with increased serum TC, LDL-C and Tg levels (59\%, $47 \%$ and $53 \%$, respectively) were higher in NAFLD compared with those of the patients with $\mathrm{CHC}$ with steatosis $(p<0.001)$. Low serum HDL-c levels $(41 \%)$ were also more common among patients with NAFLD compared with CHC+NAS ( $p=0.04)$. We found no difference in the prevalence of dyslipidemia by all criteria between the groups of $\mathrm{CHC}$ patients without steatosis and $\mathrm{HC}$.

In $\mathrm{CHC}$ patients with steatosis, the mean serum levels of TC $(p<0.001)$ and Tg $(p<0.05)$ were higher and that of HDL-c lower $(p<0.05)$ compared with the $\mathrm{CHC}$ patients without steatosis and $\mathrm{HC}$ (Table 1). The mean level of serum LDL-c $(p<0.05)$ in patients with $\mathrm{CHC}$ without steatosis was lower than in the group of $\mathrm{CHC}$ patients with steatosis and $\mathrm{HC}$. The mean serum levels of TC, LDL-C, and Tg in NAFLD patients were higher than in $\mathrm{CHC}$ with and without steatosis and $\mathrm{HC}$ $(p<0.001)$, and the mean levels of HDL-c were lower $(p<0.05$ and $p=0.001$, resp. $)$. a)

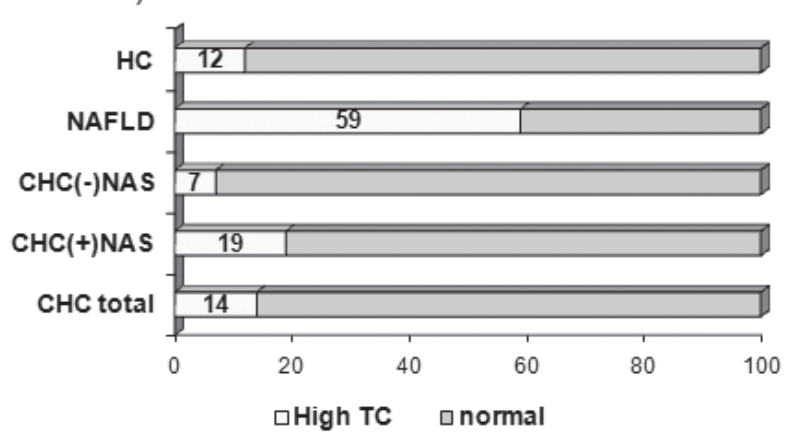

c)

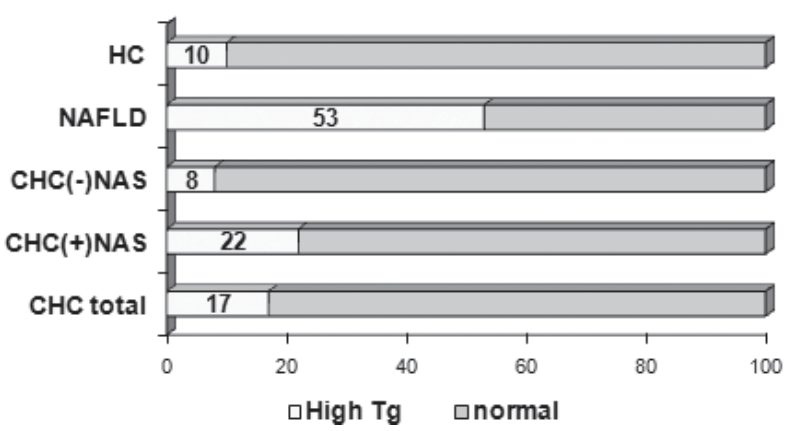

b)

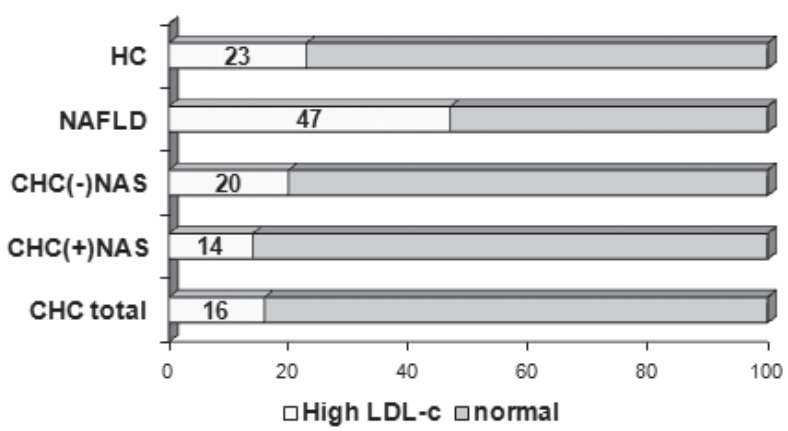

d)

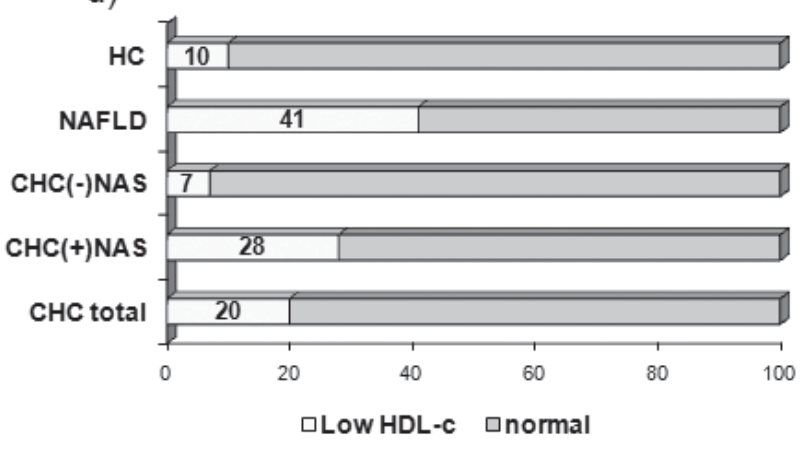

Fig. 1 a, b, c, d. Prevalence of serum lipid abnormalities (\%) in patients with $\mathrm{CHC}$ with and without NAS, NAFLD and HC: a) Total cholesterol, mmol/l (TC); b) Low-density lipoprotein-cholesterol, mmol/l (LDL-c); c) Triglycerides, mmol/l (Tg); d) High density lipoprotein-cholesterol, mmol/l (HDL-c)

Table 1. Mean levels ( \pm Standard deviation) of serum lipids $(\mathrm{mmol} / \mathrm{l})$ in patients with $\mathrm{CHC}$ with and without nonalcoholic steatosis NAS, NAFLD and HC

\begin{tabular}{|l|c|c|c|c|}
\hline \multirow{2}{*}{ Serum lipids } & \multicolumn{2}{|c|}{ CHC $(\mathbf{n}=\mathbf{3 6 6})$} & \multirow{2}{*}{$\begin{array}{c}\text { NAFLD } \\
(\mathbf{n}=\mathbf{4 0 3})\end{array}$} & $\begin{array}{c}\text { HC } \\
(\mathbf{n}=\mathbf{2 4 1})\end{array}$ \\
\cline { 2 - 3 } & $(+)$ NAS $(\mathbf{n}=\mathbf{2 2 7})$ & $(-)$ NAS $(\mathbf{n}=\mathbf{1 3 9})$ & $5.75 \pm 1.30$ & $4.83 \pm 0,88$ \\
\hline TC & $5.05 \pm 1.62$ & $4.52 \pm 1,23$ & $3.42 \pm 1.12$ & $2.76 \pm 0.88$ \\
\hline LDL-C & $2.72 \pm 0.57$ & $2.40 \pm 0.62$ & $1.26 \pm 0.34$ & $1.39 \pm 0.35$ \\
\hline HDL-C & $1.30 \pm 0.50$ & $1.38 \pm 0.49$ & $2.35 \pm 2.44$ & $1.03 \pm 0.61$ \\
\hline Triglycerides & $2.04 \pm 0.93$ & $0.98 \pm 1.22$ & \\
\hline
\end{tabular}


Metabolic abnormalities in patients with $\mathrm{CHC}$ with and without steatosis, NAFLD and HC

The prevalence and degree of other metabolic abnormalities were also higher in NAFLD and $\mathrm{CHC}+\mathrm{NAS}$ than $\mathrm{CHC}$ without steatosis and $\mathrm{HC}(\mathrm{p}<0.05$ and $\mathrm{p}$ $=0.001$, resp.) (Table 2$)$. Obesity $(p=0.03)$, abdominal obesity $(p<0.001)$ and arterial hypertension $(p<$ 0.001 ) were more prevalent in NAFLD patients than in $\mathrm{CHC}$ patients with steatosis. There was no significant difference in the proportions of overweight, MS, impaired fasting glucose, and type 2 DM between the groups with steatosis ( $\mathrm{CHC}$ with steatosis and NAFLD). Insulin resistance, evaluated by HOMA-IR, was commonly found in both groups of patients with steatosis - NAFLD and CHC+NAS. The mean levels of serum fasting glucose and insulin, as well as HOMA-IR, were also higher in patients with steatosis (NAFLD and CHC+NAS) than in those without steatosis ( $\mathrm{CHC}$ without steatosis and $\mathrm{HC})(\mathrm{p}<0.001)$ (Table 3).

Table 2. Prevalence of metabolic abnormalities in patients with $\mathrm{CHC}$ with and without NAS, NAFLD and HC

\begin{tabular}{|c|c|c|c|c|}
\hline \multirow{2}{*}{ Metabolic factors } & \multicolumn{2}{|c|}{$\mathrm{CHC}(n=366)$} & \multirow{2}{*}{$\begin{array}{l}\text { NAFLD } \\
(n=403)\end{array}$} & \multirow{2}{*}{$\begin{array}{c}\mathrm{HC} \\
(n=241)\end{array}$} \\
\hline & $(+)$ NAS $(n=227)$ & $(-)$ NAS $(n=139)$ & & \\
\hline Obesity & $33 \%$ & $1 \%$ & $50 \%$ & $6 \%$ \\
\hline Overweight & $44 \%$ & $15 \%$ & $40 \%$ & $20 \%$ \\
\hline Metabolic syndrome & $48 \%$ & $3 \%$ & $46 \%$ & $12 \%$ \\
\hline Abdominal obesity & $80 \%$ & $12 \%$ & $91 \%$ & $31 \%$ \\
\hline Arterial hypertension & $32 \%$ & $4 \%$ & $59 \%$ & $17 \%$ \\
\hline Fasting glucose $>5.6 \mathrm{mmol} / \mathrm{l}$ & $42 \%$ & $16 \%$ & $46 \%$ & $15 \%$ \\
\hline Diabetes mellitus type 2 & $20 \%$ & $6 \%$ & $19 \%$ & Exclusion criterion \\
\hline HOMA-IR $>2.5$ & $86 \%$ & $13 \%$ & $82 \%$ & $19 \%$ \\
\hline
\end{tabular}

Table 3. Mean levels ( \pm Standard deviation) of fasting glucose $(\mathrm{mmol} / \mathrm{l})$ and insulin $(\mu \mathrm{IU} / \mathrm{ml})$, and HOMA-IR in patients with $\mathrm{CHC}$ with and without NAS, NAFLD and $\mathrm{HC}$.

\begin{tabular}{|l|c|c|c|c|}
\hline \multirow{2}{*}{ Parameters } & \multicolumn{2}{|c|}{ CHC $(\mathbf{n}=\mathbf{3 6 6})$} & \multirow{2}{*}{ NAFLD } & HC \\
\cline { 2 - 3 } & $(\mathbf{n}=\mathbf{4 0 3})$ & NAS $(\mathbf{n}=\mathbf{2 2 7})$ & $(-)$ NAS $(\mathbf{n}=\mathbf{1 3 9})$ & $\mathbf{2 4 1})$ \\
\hline Fasting glucose & $5.78 \pm 1.72$ & $4,82 \pm 1,00$ & $5.82 \pm 0.61$ & $5.15 \pm 0.52$ \\
\hline Fasting insulin & $22.62 \pm 12.27$ & $13.05 \pm 4.24$ & $17.72 \pm 11.42$ & $7.31 \pm 2.46$ \\
\hline HOMA-IR & $4.88 \pm 3.25$ & $1.92 \pm 1.34$ & $4.50 \pm 3.11$ & $1.66 \pm 2.93$ \\
\hline
\end{tabular}
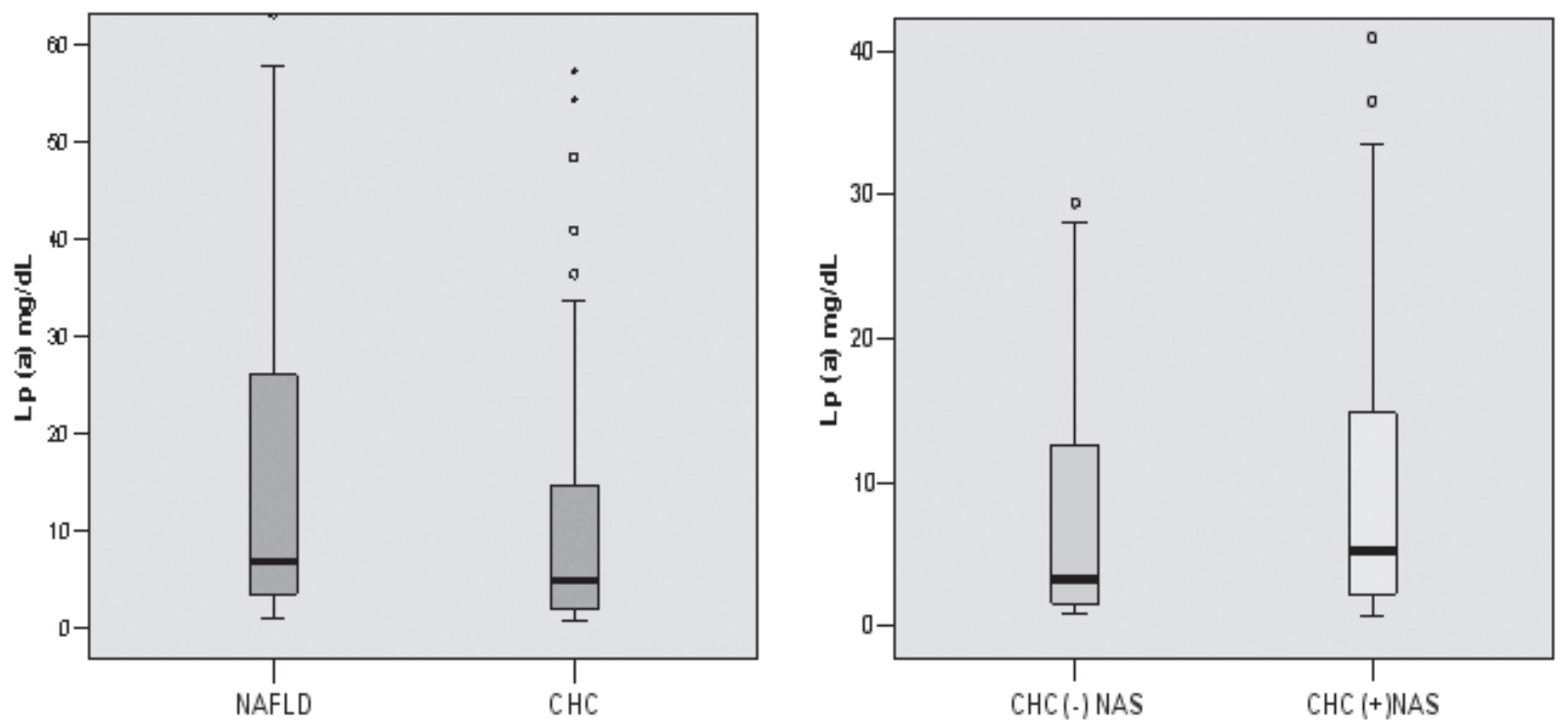

Fig. 2. Serum levels of $L p(a)$ in patients with NAFLD and $C H C$ with and without NAS 
Evaluation of $L p(a)$ levels in patients with NAFLD and $\mathrm{CHC}$

Increased $L p(a)$ was found in 17 of 112 patients with $\mathrm{CHC}$ and 19 of 80 patients with NAFLD, $15 \%$ and $24 \%$, respectively. The mean level of $L p(a)$ was higher in NAFLD than CHC group ( $p=0.016)$, but there was no difference between $\mathrm{CHC}$ patients with and without steatosis (Figure 2). Increased Lp(a) levels in both NAFLD and CHC patients showed no relation to patients' age, sex, the presence of obesity, impaired fasting glucose, arterial hypertension or MS. In NAFLD patients with increased $L p(a)$, but not in $\mathrm{CHC}$ groups, the serum level of LDL-C $(p=0.036)$ was higher compared to those with normal $L p(a)$. There was also a positive correlation between the serum levels of $L p(a)$ and LDL-c in NAFLD $(r=0.430$, $\mathrm{p}<0.001)$.

\section{DISCUSSION}

Serum lipid disorders are common in chronic liver disease with viral and non-viral etiology as the liver is the principal site of lipoprotein formation and metabolism. In this study, we evaluated the serum lipid alterations in a large number of young and middleaged genotype 1 , treatment - naïve $\mathrm{CHC}$ patients with and without nonalcoholic steatosis on histology and compared them with those with NAFLD, and HC without steatosis on liver ultrasound.

Our results showed that the prevalence of dyslipidemia was significantly higher in patients with $\mathrm{CHC}$ with steatosis (high Tg or low HDL-C) and NAFLD (high TC, high LDL-C, high Tg or low HDL-C) than in those with $\mathrm{CHC}$ without steatosis and HC. Among NAFLD patients, high TC was the most common criteria for dyslipidemia, followed by high Tg, high LDL-C, and low HDL-c, while in those with $\mathrm{CHC}$ with steatosis low HDL-c was the most common lipid abnormality, followed by high $\mathrm{Tg}$ and high TC. The mean level of LDL-C was lower in $\mathrm{CHC}$ without steatosis than in any other group - $\mathrm{CHC}$ with steatosis, NAFLD, and HC. In both groups of patients with steatosis ( $\mathrm{CHC}$ and NAFLD), we evaluated a significantly higher prevalence of other metabolic derangements in comparison with the groups without steatosis ( $\mathrm{CHC}$ and $\mathrm{HC})$. Despite the difference in types of dyslipidemia in genotype $1 \mathrm{CHC}$ and NAFLD patients, insulin resistance is the main cause for increased cardiovascular risk in both chronic liver diseases. Our results are in concordance with the literature data that in patients with genotype $1 \mathrm{CHC}$ steatosis is "metabolic" and related with obesity, arterial hypertension, dysglycemia, type 2DM, MS, abdominal obesity and IR [1, 3, 4]. The high prevalence of IR in $\mathrm{CHC}$ with steatosis has been reported to be due to the HCV infection and NAS independently or together [14]. Increased levels of proinflammatory cytokines interleukin-6 (IL-6) and tumor necrosis factor alpha (TNF- $\alpha$ ) in patients with $\mathrm{CHC}$ and visceral obesity also contribute to development of liver steatosis and IR [15]. A metaanalysis has shown that $\mathrm{CHC}$ patients have about 1.7 -fold increased risk of development type 2 DM compared with noninfected controls [16]. The mechanism involved in HCV-induced type $2 \mathrm{DM}$ is IR, which is associated with both viral infection and steatosis. Although lower serum levels of TC, LDL-C and HDL-C are commonly reported in treatment naïve $\mathrm{CHC}$ patients when compared with those of normal subjects, the literature data on the impact of steatosis on serum lipids levels are limited $[2,17,18]$. Lipids play an important role in multiple aspects of HCV life cycle as HCV modulates host lipoprotein metabolism to make it more effective for viral proliferation, propagation and persistence [4, $19,20]$. HCV-associated hypocholesterolemia results from the inhibition of apolipoprotein B 100 secretion and disturbed distal cholesterol synthesis pathway [21]. Several authors confirm a higher prevalence of atherogenic dyslipidemia with increased serum $\mathrm{Tg}$, decreased HDL-c levels in $\mathrm{CHC}+\mathrm{NAS}$ compared with $\mathrm{CHC}$ patients without steatosis and $\mathrm{HC}[22,23]$. In genotype $1 \mathrm{CHC}$ patients HOMA-IR and serum triglycerides levels increased progressively from $\mathrm{CHC}$ to $\mathrm{CHC}+\mathrm{NAS}$ to $\mathrm{CHC}+$ nonalcoholic steatohepatitis [22]. Other authors have also reported that patients with $\mathrm{CHC}+\mathrm{NAS}$ had higher serum $\mathrm{Tg}$ levels than those without steatosis [23].

We also assessed and compared serum $L p(a)$ levels in subgroups of patients with NAFLD and CHC with and without steatosis. $L p(a)$ has been recognized as an independent genetic risk factor for cardiovascular disease [24-26]. Numerous studies have found a correlation between elevated $L p(a)$ plasma levels and coronary heart disease, stroke, and peripheral atherosclerosis. Although $L p(a)$ concentrations are mostly determined by genetic factors, they can be influenced to a minor extent by apo(a) gene-independent effects, including diet, age, hormonal status and some diseases (familial hypercholesterolemia, renal and liver diseases). Our results showed a similar prevalence of increased $L p(a)$ levels in both groups of patients but the mean level of $L p(a)$ in NAFLD patients was significantly higher compared with $\mathrm{CHC}$ ones, irrespective of the presence of steatosis. We found no relation between serum levels of $L p(a)$ and patients age, sex and evaluated metabolic parameters. The literature data on more or less significant variations between NAFLD and $\mathrm{CHC}$ patients are also limited [27-30]. Several studies have reported increased serum $L p(a)$ levels 
among cases with MS, obesity or diabetes, but other authors did not find such relationship [28]. Reduced serum levels of $L p(a)$ have been found in patients with various viral induced liver diseases compared with $\mathrm{HC}$ [29]. A significant increase of baseline serum $L p(a)$ concentrations has been reported in $\mathrm{CHC}$ patients after interferon treatment and it has been assumed that this increase reflects an improvement of liver function [30]. More detailed studies are needed to elucidate the possible variation in serum $L p(a)$ levels between patients with NAFLD and CHC.

In conclusion, lipid and glucose metabolic abnormalities in patients with genotype $1 \mathrm{CHC}$ are dependent on steatosis. $\mathrm{CHC}$ with steatosis and NAFLD are associated with insulin resistant type of dyslipidaemia, with total cholesterol and LDL-cholesterol being generally lower in $\mathrm{CHC}$.

\section{Acknowledgments}

The study was funded by research grant No. 14 D/2014 from Medical University of Sofia, Bulgaria. Serum samples were analyzed in Clinical Laboratory of University Hospital "Sv. Ivan Rilski".

\section{REFERENCES}

1. Lonardo A, Adinolfi LE, Loria P et al. Steatosis and hepatitis C virus: Mechanisms and significance for hepatic and extrahepatic disease. - Gastroenterology 2004, 126, 586-597.

2. Loria P, Marchesini G, Nascimbeni $F$ et al. Cardiovascular risk, lipidemic phenotype and steatosis. A comparative analysis of cirrhotic and non-cirrhotic liver disease due to varying etiology. - Atherosclerosis. 232, 2014, 1, 99-109.

3. Adinolfi LE, Rinaldi L, Guerrera B et al. NAFLD and NASH in HCV Infection: Prevalence and Significance in Hepatic and Extrahepatic Manifestations. - Int J Mol Sci., 2016, 17(6).

4. Lonardo A, Adinolfi LE, Restivo L et al. Pathogenesis and significance of hepatitis $C$ virus steatosis: an update on survival strategy of a successful pathogen. World J Gastroenterol. 20, 2014, 23:7089-103.

5. Asselah T, Rubbia-Brandt L, Marcellin P, Negro F. Steatosis in chronic hepatitis C: why does it really matter? - Gut. 2006; 55(1):123-30.

6. Adinolfi LE, Restivo L, Zampino R et al. Chronic HCV infection is a risk of atherosclerosis. Role of HCV and HCV-related steatosis. - Atherosclerosis.221, 2012, 2, 496-502.

7. Bhatia LS, Curzen NP, Calder PC, Byrne CD. Nonalcoholic fatty liver disease: a new and important cardiovascular risk factor? - Eur Heart J. 33, 2012, 10, 1190-2000.

8. Targher G, Day CP, Bonora E. Risk of cardiovascular disease in patients with nonalcoholic fatty liver disease. N Engl J Med, $363,2010,14,1341-50$

9. Defilippis AP, Blaha MJ, Martin SS, et al. Nonalcoholic fatty liver disease and serum lipoproteins: the Multi-Ethnic Study of Atherosclerosis. Atherosclerosis 227, 2013, 2, 429-36.

10. EASL Clinical Practice Guidelines: management of hepatitis C virus infection. J Hepatol. 2014; 60(2):392-420.
11. EASL (European Association for the Study of the Liver) EASD (European Association for the Study of Diabetes) EASO (European Association for the Study of Obesity) Clinical Practice Guidelines for the management of non-alcoholic fatty liver disease. J Hepatol. 2016; 64(6):1388-402.

12. Alberti KG, Zimmet $P$, Shaw J. Metabolic syndrome - a new world-wide definition. A Consensus Statement from the International Diabetes Federation. Diabet Med. 23, 2006, 5, 469-80.

13. WHO/IDF Report, Definition and diagnosis of diabetes mellitus and intermediate hyperglycemia, 2006.

14. Vanni E, Abate ML, Rizzetto $M$ et al. Sites and mechanisms of insulin resistance in nonobese, nondiabetic patients with chronic hepatitis C. Hepatology. 2009 Sep;50(3):697-706.

15. Jonsson JR, Barrie HD, O'Rourke P et al. Obesity and steatosis influence serum and hepatic inflammatory markers in chronic hepatitis C. Hepatology 48, 2008, 1, 80-87.

16. White DL, Ratziu V, El-Serag HB. Hepatitis C infection and risk of diabetes: a systematic review and meta-analysis. $\mathrm{J}$ Hepatol. 49, 2008, 5, 831-44.

17. Siagris D, Christofidou M, Theocharis GJ et al. Serum lipid pattern in chronic hepatitis $\mathrm{C}$ : histological and virological correlations. J Viral Hepat. 13, 2006, 1, 56-61.

18. Hsu CS, Liu CJ, Liu CH et al. Metabolic profiles in patients with chronic hepatitis C: a case-control study. - Hepatol Int. 2, 2008, 2, 250-7.

19. Blaising J, Pécheur El. Lipids: a key for hepatitis $C$ virus entry and a potential target for antiviral strategies. Biochimie 95, 2013; 1, 96-102.

20. Syed GH, Tang H, Khan M et al. Hepatitis $\mathrm{C}$ virus stimulates low-density lipoprotein receptor expression to facilitate viral propagation. J Virol. 88, 2014, 5, 2519-29.

21. Clark PJ, Thompson AJ, Vock DM et al. Hepatitis C virus selectively perturbs the distal cholesterol synthesis pathway in a genotype-specific manner. Hepatology 56, 2012, 1, 49-56.

22. Bedossa P, Moucari R, Chelbi E et al. Evidence for a role of nonalcoholic steatohepatitis in hepatitis C: a prospective study. Hepatology. 46, 2007, 2, 380-7.

23. Ramcharran D, Wahed AS, Conjeevaram HS et al. Serum lipids and their associations with viral levels and liver disease severity in a treatment-naïve chronic hepatitis $C$ type 1 -infected cohort. J Viral Hepat. 18, 2011, 4, e144-52.

24. Berglund L, Ramakrishnan R. Lipoprotein(a): an elusive cardiovascular risk factor. Arterioscler Thromb Vasc Biol. 24, 2004, 12, 2219-26.

25. Børge G. Nordestgaard BG, Chapman MJ et al. And for the European Atherosclerosis Society Consensus Panel. Lipoprotein(a) as a cardiovascular risk factor: current status. Eur Heart J. 31, 2010, 23, 2844-2853.

26. Ohira T, Schreiner PJ, Morrisett JD, et al. Lipoprotein(a) and incident ischemic stroke: the Atherosclerosis Risk in Communities (ARIC) study. Stroke. 37, 2006, 6, 1407-12.

27. Yang $M H$, Son HJ, Sung JD et al. The relationship between apolipoprotein E polymorphism, lipoprotein (a) and fatty liver disease. Hepato-gastroenterology 52, 2005, 66, 1832-1835.

28. Bozbaş $\mathrm{H}$. et al. Increased lipoprotein(a) in metabolic syndrome: is it a contributing factor to premature atherosclerosis? Anadolu Kardiyol Derg. 8, 2008, 2, 111-5.

29. Malaguarnera M, Giugno I, Trovato BA et al. Lipoprotein(a) concentration in patients with chronic active hepatitis $C$ before and after interferon treatment. Clin Ther. 17,1995,4, 721-8.

30. Irshad M. Serum lipoprotein (a) levels in liver diseases caused by hepatitis. Indian J Med Res. 120, 2004, 6:542-5. 